\title{
PERANGKINGAN DAN PERAMALAN PENJUALAN PERUMAHAN MENGGUNAKAN METODE SIMPLE ADDITIVE WEIGHTING DAN DOUBLE EXPONENTIAL SMOOTHING
}

\author{
Sidiq Eko Budiharjo ${ }^{1}$, Wiwien Hadikurniawati ${ }^{2}$ \\ ${ }^{1,2}$ Program Studi Teknik Informatika, Fakultas Teknologi Informasi, Universitas Stikubank \\ e-mail: ${ }^{1}$ sidiqekob90@gmail.com, ${ }^{2}$ wiwien@edu.unisbank.ac.id
}

\begin{abstract}
Abstrak
Kemudahan proses pembelian rumah menyebabkan peningkatan permintaan akan produksi rumah. Citragrand merupakan satu dari banyak perusahaan real estate di Semarang, Jawa Tengah. Penjualan yang tidak menentu setiap bulannya, membuat perusahaan kesulitan dalam menentukan target penjualan pada awal tahun dan juga dalam menentukan top product di tahun tersebut. Dengan masalah tersebut, perusahaan membutuhkan solusi yang dapat meramalkan penjualan di tahun mendatang, serta menentukan tipe rumah apa yang bisa menjadi top product hingga penjualan paling sedikit, sehingga dapat memperbaiki kualitas rumah dan menguntungkan perusahaan. Peramalan penjualan atau forecasting adalah metode analisa perhitungan dengan hasil perkiraan peristiwa di masa depan yang membutuhkan data masa lalu sebagai referensi dan memakai pendekatan kualitatif ataupun kuantitatif. Forecasting yang digunakan dalam hal ini menggunakan metode Double Exponential Smoothing. Selain di ramalkan penjualannya, juga dilakukan proses perangkingan produk perumahan terbaik yang dihitung menggunakan metode simple additive weighting (SAW). Dengan menggabungkan forecasting dan perangkingan produk, diharapkan mampu mengatasi salah satu masalah penjualan yang dialami oleh perusahaan Citragrand Semarang. Kedua metode ini dibuat dengan berbasis website yang dibangun dengan bahasa permrogaman PHP dan framework Codeigniter sebagai server program. Hasil dari sistem ini yaitu Sistem Pendukung keputusan dan peramalan dengan tujuan mendapatkan hasil top product dan peramalan penjualan untuk tahun berikutnya.
\end{abstract}

Kata Kunci: SAW, Double Exponential Smooting, Forecasting, Perangkingan produk

\section{PENDAHULUAN}

Sektor industri real estate mengalami perkembangan yang signifikan dan merupakan penyumbang pajak terbesar kepada negara. Di Indonesia khususnya Kota Semarang, developer real estate semakin banyak dan muncul para kompetitor baru. Persaingan para pelaku bisnis ini semakin terasa dengan munculnya banyak inovasi terutama dari segi produk dan pemasaran mereka. Revolusi industri 4.0 adalah upaya mengintegrasikan antara online system di hampir semua sektor pada perusahaan. Teknologi internet menjadi hal penting dalam proses ini. Berkat kecanggihan industri 4.0 yang mengandalkan kemampuan teknologi sistem cerdas dan otomasi, menjadikan persaingan perusahaan dengan kompetitor menjadi semakin ketat.

Ciputra merupakan salah satu pengembang real estate yang terkemuka di Indonesia yang mempunyai proyek di Indonesia dan beberapa di mancanegara. Salah satu proyek real estate yang terdapat di Kota Semarang, Jawa Tengah adalah CitraGrand. Perumahan CitraGrand saat ini memiliki 6 private cluster dengan berbagai tipe rumah di dalamnya. Agar tidak ketinggalan pada era industri 4.0, CitraGrand sedang berupaya membangun infrastruktur teknologi dalam membantu proses penjualan. Dengan omzet dan berbagai jenis tipe rumah yang cukup banyak, sehingga data transaksi yang dihasilkan belum dapat diolah secara maksimal untuk kebutuhan sistem manajemen real estate saja. Tidak adanya sistem bantu yang dapat menangkap keperluan dan kebutuhan konsumen akan rumah, membuat developer terus membuat tipe rumah baru yang sesuai dengan intuisi manajemen saja. Padahal jika kita tarik dari laporan 
penjualan tersebut dan kita olah, dapat juga menghasilkan sistem pendukung keputusan dan membantu perusahaan untuk meningkatkan kualitas produk dan omzet perusahaan.

Dari hal tersebut, tentunya perlu sebuah solusi yang dapat mengatasi masalah dalam mengelola transaksi penjualan perumahan yang sekaligus dapat meramalkan dan merangkingkan penjualan perumahan. Sehingga target penjualan pada periode yang akan datang dapat ditentukan oleh perusahaan. Salah satu solusi yang dirasa cukup tepat dan efektif dalam mengatasi masalah diatas yaitu sistem informasi peramalan dan perangkingan penjualan perumahan yang berbasis website. Dengan semakin berkembangnya teknologi informasi dizaman sekarang ini, website dirasa cukup tepat untuk membantu proses olah data dan proses perangkingan serta peramalan penjualan yang dibangun dengan metode SAW dan Double Exponential Smoothing.

\section{TINJAUAN PUSTAKA}

Pada penelitian pertama pernah membahas mengenai metode simple additive weighting pada sistem pendukung keputusan pada pencarian properti perumahan yang dilakukan oleh [1]. Dari penelitian ini menghasilkan sistem yang berguna dalam memberikan alternatif kepada customer dalam memilih perumahan yang sesuai dengan kriteria. Selanjutnya, peneliti [2], melakukan penelitian tentang sistem pemilihan rumah dengan metode SAW. Kelebihan dari kedua penelitian ini adalah atribut-atribut yang diambil sudah merujuk kepada masalah yang ada, sehingga didapat hasil yang lebih akurat dan sesuai dengan kebutuhan. Berikutnya [3], dilakukan penelitian penerapan peramalan produksi tanaman dengan metode Double Exponential Smoothing dan hasil yang diperoleh dari sistem ini mampu menghasilkan peramalan dengan nilai percentage error sebesar $2.22 \%$. pada tahun sebelumnya, peneliti [4], konsen membuat penelitian peramalan dengan metode Double Exponential Smoothing pada Index Harga Konsumen (IHK) dan mampu menghasilkan tingkat percentage error sebesar 2.1421 dengan nilai alpha 0.61. Dan yang terakhir penelitian dilakukan [5] mengenai Sistem Pendukung Keputusan pemilihan hotel dengan metode SAW. Output sistem yang dihasilkan adalah penilaian perangkingan yang sesuai dengan data, karena berdasar dengan kriteria dan bobot prefrensi yang sudah ditentukan dan sistem yang digunakan sudah online, sehingga data di seluruh hotel selalu update dan data sudah tersentralisasi dengan baik.

\subsection{Simple Additive Weighting (SAW)}

Simple additive weighting ini sering digunakan sebagai salah satu cara dalam pengambilan keputusan dengan suatu metode penjumlahan terbobot. Sebelum diperbandingkan dengan rating semua alternatif, terlebih dahulu dilakukan proses normalisasi matriks keputusan (X) pada rasio tertentu. Metode SAW ini banyak sekali dipakai dalam persoalan Multi-Attribute Decision Making (MADM) untuk mencari alternatif yang paling baik dari berbagai alternatif dengan atribut tertentu.

Dalam menyelesaikan permasalahan menggunakan metode ini terdapat beberapa tahapan yang perlu dilakukan antara lainnya adalah [6]:

1) Langkah awal adalah penentuan atribut dari kriteria sebagai referensi pengambilan keputusan yaitu $\mathrm{Ci}$

2) Kemudian dari tiap kriteria yang telah dibuat sebelumnya, akan ditentukan nilai rating kecocokannya.

3) Lalu membuat sebuah matriks keputusan yang berasal dari kriteria yang dibuat tadi (Ci), setelah itu dilakukan normalisasi matriks berdasarkan persamaan yang disesuaikan dengan jenis atribut (baik itu atribut cost atau benefit) sehingga didapati matriks yang ternormalisasi $\mathrm{R}$. 
4) Hasil perangkingan dari alternatif diperole dengan cara menjumlahkan dari hasil kali martiks R dengan bobot kriteria. nilai paling tinggi akan dipilih sebagai alternatif (Ai) solusi dari suatu permasalahan.

Berikut adalah formula untuk menyelesaikan normalisasinya adalah:

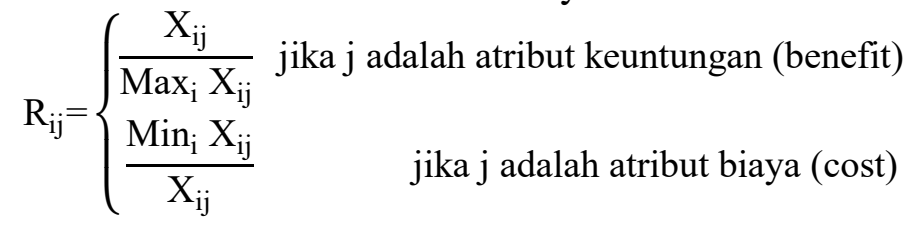

Dimana:

Rij = rating kinerja ternormalisasi

Maxij = nilai maksimum dari setiap baris dan kolom

Minij = nilai minimum dari setiap baris dan kolom

$\mathrm{Xij}=$ baris dan kolom dari matriks

Dengan rij adalah rating kinerja ternormalisasi dari alternatif $\mathrm{Ai}$ pada atribut $\mathrm{Cj}$; $\mathrm{i}=1,2, \ldots \mathrm{m}$ dan $\mathrm{j}=1,2, \ldots, \mathrm{n}$.

\subsection{Double Exponential Smoothing}

Exponential smoothing atau jika diterjemahkan berarti penghalusan eksponential adalah suatu metode peramalan yang menganalisa deret waktu atau time series dengan pembobotan secara bertingkat pada data-data terkini yang menjadikan data-data terbaru itu akan memperoleh bobot yang lebih besar. Pemberian bobot yang besar ini dikaranakan data terkini tersebut dianggap paling relevan. Parameter penghalusan (smoothing) biasanya dilambangkan dengan $\alpha$ (alpha). Double Exponential Smoothing adalah metode model linier yang di temukan oleh brown.. Ketika data menunjukkan adanya suatu pergerakan harga, maka metode ini yang akan digunakan. Pergerakan harga atau trend merupakan salah satu cara perkiraan kuntitatif dari penghalusan rata-rata pertumbuhan. Berdasarkan analogi yang digunakan pada Single Moving Average ke Single Exponential Smoothing maka dapat pula berangkat dari Double Moving Average ke Double Exponential Smoothing. Brown menyatakan bahwa pola pada metode Double Moving Average yaitu karena kedua nilai Single Smoothing dan Double Smoothing tertinggal dari data nilai yang sebenarnya jika terdapat unsur trend. Perbedaan antara nilai Single Smoothing dan Double Smoothing (S - S ) dapat ditambahkan pada nilai single smoothing ( $\mathrm{S}$ ) dan disesuaikan untuk trend. Beberapa cara perhitungan yang bisa dipakai pada penerapan Double Exponential Smoothing yang dikemukakan oleh Brown yaitu seperti berikut ini :

1) Mencari nilai penghalusan pertama dengan (S) $S=\alpha X+(1-\alpha) S$

2) Mencari nilai penghalusan kedua dengan $(S) S=\alpha S+(1-\alpha) S$

3) Pencarian nilai tetapan (at) $a=2 S-S$

4) Mencari nilai kemiringan dengan (bt) bt $=\alpha 1 \alpha(\mathrm{St}-\mathrm{St})$

5) Langkah terakhir adalah menghitung nilai peramalan dengan $F=a+b m$

Untuk mencari perhitungan tersebut, maka nilai St-1danSt-1 harus terpenuhi. Namun jika $t$ $=1$, nilai-nilai tersebut tidak tersedia. Karena nilai tersebut harus didapatkan dari awal periode, solusi dari masalah ini yaitu dapat digunakan dengan menetapkan nilai S1 dan S1 sama dengan nilai X1 (data aktual).

\subsection{Pemilihan Parameter $\alpha$ Terbaik}

Ketepatan dalam sebuah peramalan menjadi salah satu kriteria dalam menentukan suatu metode yang digunakan dalam peramalan. Bagi pengguna suatu hasil ramalan, faktor ketepatan menjadi faktor yang penting. Pengukuran ketepatan suatu peramalan dapat dilihat dari tingkat kesalahan hasil akhir peramalan sebagai pembanding dengan metode lain. Salah satu cara yang 
digunakan dalam pemilihan suatu metode forecasting dengan tingkat kesalahan terkecil adalah dengan menggunakan metode Mean Absolute Percentage Error atau dapat disingkat dengan MAPE.

$$
\mathrm{MAPE}=\sum|\mathrm{PE}|
$$

Dimana PE adalah persentase tingkat kesalahan dari peramalan dalam suatu periode (percentage error):

$$
\mathrm{PE}=100 \%
$$

Dari formula diatas dapat diartikan bahwa semakin kecil nilai MAPE pada suatu periode peramalan, maka hasil dari nilai peramalan merupakan hasil yang akurat dan mendekati nilai sebenarnya pada periode mendatang. Sehingga metode tersebut adalah metode yang paling baik digunakan. Solusi dari permasalahan ini adalah menggunakan metode double exponential smooting Brown. Model pencarian nilai MAPE untuk memperoleh nilai alpha $(\alpha)$ terbaik akan dilakukan secara empiris atau melalui pengujian. Nilai alpha diperoleh dari suatu kisaran nilai tertentu (biasanya kisaran $0 \mathrm{~s} / \mathrm{d}$ 1). Dengan adanya kisaran nilai alpha yang relatif sedikit ini, sehingga metode yang dikemukakan oleh Brown (double exponential smoothing) seringkali dipakai dibanding dengan metode lainnya.

\subsection{Forecasting}

Forecasting atau yang juga bisa disebut dengan peramalan adalah suatu hal yang digunakan untuk mendapatkan data perkiraan dimasa mendatang yang meliputi nilai kualitas atau kuantitas, periode, dan tempat dimana produk tersebut dibutuhkan. forecasting juga dapat digunakan sebagai fungsi bisnis yang dapat memperkirakan nilai jual produk, nilai permintaan pasar, jumlah stok di periode waktu yang akan datang. forecasting pada dasarnya adalah suatu perhitungan ilmiah untuk memprediksi tentang terjadinya beberapa hal di periode mendatang. Setiap pengambilan hasil yang bersangkutan dengan keadaan di waktu yang akan datang, maka pasti ada prakiraan yang jadi landasan dari hasil yang didapat tersebut. Prakiraan merupakan teknik dalam menggunakan data dari masa lalu dengan sebuah variabel atau kumpulan variabel untuk mendapatkan kira - kira nilai di periode berikutnya. Pola pikir awal dalam teknik ini adalah: "if we can predict what the future will be like we can modify our behaviour now to be in a better position, than we otherwise would have been, when the future arrives". Yang berarti,dengan memperkirakan sesuatu yang mungkin akan terjadi di masa datang, kita dapat mengubah perilaku yang biasa kita lakukan menjadi lebih baik daripada sebelumnya. Suatu kebiasaan dimasa lalu akan terulang dimasa depan meskipun dalam jangka waktu yang relatif singkat.

\section{HASIL DAN PEMBAHASAN}

Setelah menyelesaikan tahapan analisa dan desain sistem, Langkah berikutnya akan dilakukan proses implementasi

Setelah melakukan analisis dan desain sistem, maka dilanjutkan dengan pengkodingan program agar didapatkan sistem perangkingan produk paling laku dan peramalan penjualan yang tepat guna.

\subsection{Login}

Pada saat pengguna membuka halaman web, sistem akan mengarahkan ke laman login, setiap pengguna diberikan akses berupa username dan password masing - masing. 


\subsection{Form Penjualan}

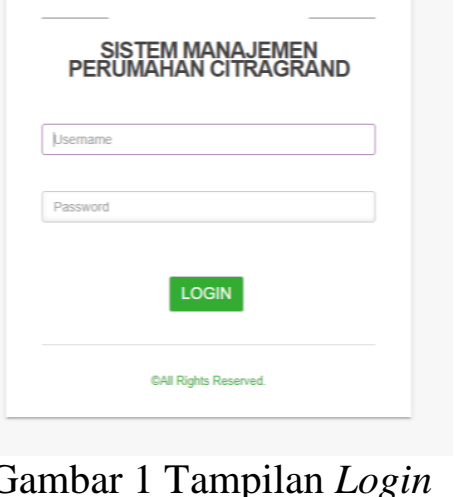

Form penjualan di sistem ini menggunakan metode point of sale dimana pengguna dapat melakukan pengelolaan penjualan produk perumahan dan mendatanya dengan baik dan benar agar transaksi yang telah dilakukan dapat tercatat oleh sistem. Dimenu ini, pengguna dapat melihat sejauh mana produk perumahan telah terjual dan jenis apa saja yang paling laku dijual. Data yang telah di input dalam menu ini akan tersimpan permanen dalam database MySQL server, sehingga pengguna tidak perlu khawatir akan kehilangan data apabalia terjadi kerusakan atau gangguan terhadap perangkat elektronik yang diguanakan. Selain itu, data yang tersimpan juga dijamin kerahasiaannya, sehingga tidak sembarang orang dapat mengakses data tersebut dan menggunakan untuk kepentingan pribadi.

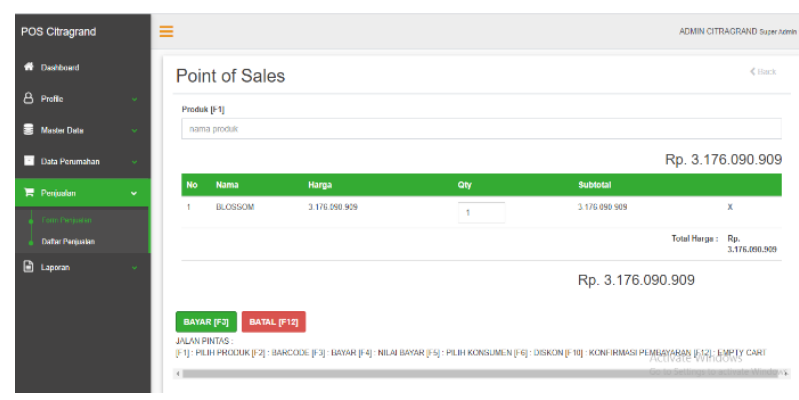

Gambar 2 Form Penjualan Produk

\subsection{Laporan Perangkingan Produk}

Perangkingan dilakukan dengan menggunakan metode SAW, dimana data yang dimasukan harus dinilai berdasarkan kriteria yang ada. Kriteria yang digunakan menggunakan dua atribute, yaitu cost dan benefit. Cost yaitu kriteria perangkingan ketika semakin rendah nilainya maka dianggap semakin baik. Sedangkan benefit, merupakan kriteria yang ketika nilainya semakin tinggi maka dianggap semakin baik.

Tabel 1. Kriteria Perangkingan

\begin{tabular}{|l|l|c|}
\hline Kriteria & Atribute & Nilai \\
\hline Jumlah Penjualan (CO1) & benefit & 5 \\
\hline Luas Bangunan (C02) & benefit & 3 \\
\hline Luas Tanah (C03) & benefit & 3 \\
\hline Jumlah Kamar (C04) & benefit & 3 \\
\hline Carpot dan Garasi (C05) & benefit & 2 \\
\hline
\end{tabular}

Nilai diatas didapatkan melalui kesepakatan dengan pengguna. Setelah didapatkan nilai diatas, maka selanjutnya menyiapkan data alternatif atau data penjualan yang akan di rangkingkan. Berikut beberapa contoh penjualan yang diambil dari sample data perusahaan CitraGrand Semarang. 
Tabel 2. Data Alternatif

\begin{tabular}{|l|c|}
\hline Nama produk & Kode Produk \\
\hline Koichi A & A01 \\
\hline Grimsby & A02 \\
\hline Eilon & A03 \\
\hline
\end{tabular}

Selanjutnya data diatas diolah dan dilakukan penilaian berdasarkan kriteria yang telah ditentukan. Penilaian dilakukan dengan melihat laporan nyata milik perusahaan sebagai pembanding pemberian nilai. Pemberian nilai bisa dalam skala $0-5$, dimana setiap produk wajib diberi nilai meskipun angkanya nol (0).

Tabel 3. Penjualan dan Nilai Produk

\begin{tabular}{|c|c|c|c|c|c|c|c|}
\hline Kode produk & C01 & C02 & C03 & C04 & C05 & C06 & C07 \\
\hline A01 & 3 & 0 & 1 & 1 & 1 & 4 & 1 \\
\hline A02 & 2 & 2 & 2 & 3 & 2 & 4 & 3 \\
\hline A03 & 2 & 2 & 2 & 3 & 2 & 4 & 3 \\
\hline
\end{tabular}

Langkah selanjutnya yaitu melakukan normalisasi nilai, dari nilai yang telah didapatkan di tabel sebelumnya. Berikut hasil perhitungannya:

Tabel 4. Normalisasi Nilai

\begin{tabular}{|l|c|c|c|c|c|c|c|}
\hline Kode produk & C01 & C02 & C03 & C04 & C05 & C06 & C07 \\
\hline A01 & 1.00 & 0.00 & 0.33 & 0.20 & 0.20 & 0.80 & 1.00 \\
\hline A02 & 0.67 & 0.67 & 0.67 & 0.60 & 0.40 & 0.80 & 0.33 \\
\hline A03 & 0.67 & 0.67 & 0.67 & 0.60 & 0.40 & 0.80 & 0.33 \\
\hline
\end{tabular}

Setelah menghitung normalisasi nilai, terakhir bisa didapatkan nilai akhir dari perangkingan produk paling laku. Tabel perangkingan produknya yaitu sebagai berikut :

Tabel 5. Hasil Total Perangkingan

\begin{tabular}{|c|r|}
\hline Kode Produk & Total Nilai Perangkingan \\
\hline A01 & 9.40 \\
\hline A02 & 12.33 \\
\hline A03 & 10.13 \\
\hline
\end{tabular}

Dari tabel diatas bisa disimpulkan bahwa produk dengan kode A02 merupakan produk paling laku, hal ini didapat karena produk A02 memiliki nilai akhir paling tinggi yaitu 12.33. Sedangkan produk A01 berada diurutan paling akhir dengan nilai akhir 9.40.

\subsection{Laporan Peramalan Penjualan}

Dari produk yang telah dirangkingkan diatas, dicari nilai penjualannya lalu di ramalkan penjualannya untuk periode yang akan datang.

Tabel 6. Penjualan

\begin{tabular}{|l|l|r|}
\hline No & Bulan & Penjualan \\
\hline 1. & Januari & 11 \\
\hline 2. & Februari & 2 \\
\hline 3. & Maret & 12 \\
\hline 4. & April & 1 \\
\hline 5. & Mei & 5 \\
\hline 6. & Juni & 4 \\
\hline 7. & Juli & 6 \\
\hline 8. & Agustus & 6 \\
\hline 9. & September & 3 \\
\hline 10. & Oktober & 5 \\
\hline 11. & November & 7 \\
\hline 12. & Desember & 0 \\
\hline
\end{tabular}


Nilai diatas kemudian diramalkan menggunakan double exponential smoothing dengan menghitung rata - rata dari bulan sebelumnya. Berikut proses perhitungan menggunakan metode double exponential smoothing.

a. Proses pertama nilai S't (1) dan S't (1) tidak diketahui, maka kita dapat menggunakan nilai observasi dengan data aktual yang pertama (X1). Berikut merupakan perhitungan peramalan pada periode Februari 2019 dengan alpha 0,1:

Perhitungan Pemulusan Tunggal

$$
\begin{aligned}
\mathrm{S} ' \mathrm{t} & =\alpha \mathrm{Xt}+(1-\alpha) \mathrm{S} ' \mathrm{t}-1 \\
& =((0,1 * 2)+((1-0,1) * 11)) \\
& =0,2+(0,9 * 11) \\
& =0,2+9,9 \\
& =10,1
\end{aligned}
$$

Perhitungan Pemulusan Ganda

$$
\begin{aligned}
\mathrm{S} ” & =\alpha \mathrm{S}^{\prime} \mathrm{t}+(1-\alpha) \mathrm{S} \prime \\
& =((0,1 * 10,1)+((1-0,1) * 11)) \\
& =1,01+(0,9 * 11) \\
& =1,01+9,9 \\
& =10,91
\end{aligned}
$$

Perhitungan pemulusan total

$$
\begin{aligned}
\text { at } & =2 \mathrm{~S}{ }^{\prime} \mathrm{t}-\mathrm{S} " \mathrm{t} \\
& =2 * 10,1-10,91 \\
& =9,29
\end{aligned}
$$

Perhitungan pemulusan Tren

$$
\begin{aligned}
\mathrm{bt} & =\alpha / 1-\alpha^{*}\left(S^{\prime} t-S^{\prime \prime} t\right) \\
& =0,1 / 1-0,1 *(10,1-10,91) \\
& =(0,1 / 0,9) *(-0,81) \\
& =-0,137
\end{aligned}
$$

b. Proses kedua nilai $S^{\prime} t(2)$ dan $S " t(2)$ pada perhitungan periode sebelumnya yaitu Februari diketahui, sehingga kita dapat menggunakan hasil perhitungan dari nilai $S$ ' $t(2)$ dan $S$ ' $t(2)$ untuk menghitung nilai $S$ 't(3) dan S'tt(3) pada periode Maret. Berikut merupakan perhitungan peramalan pada periode Maret 2019

Perhitungan Pemulusan Tunggal

$$
\begin{aligned}
\text { S't } & =\alpha X t+(1-\alpha) S^{\prime} t-1 \\
& =0,1 * 12+(1-0,1) * 10,1 \\
& =1,2+(0,9 * 10,1) \\
& =1,2+9,09 \\
& =10,29
\end{aligned}
$$

Perhitungan Pemulusan Ganda

$$
\begin{aligned}
\mathrm{S} ” t & =\alpha \mathrm{S}^{\prime} \mathrm{t}+(1-\alpha) \mathrm{S}{ }^{\prime} \mathrm{t}-1 \\
& =0,1 * 10,29+(1-0,1) * 10,91 \\
& =1,029+(0,9 * 10,91) \\
& =1,029+9,819 \\
& =10,848
\end{aligned}
$$

Perhitungan pemulusan total

$$
\begin{aligned}
\text { at } & =2 \mathrm{~S}^{\prime} \mathrm{t}-\mathrm{S}{ }^{\prime \prime} \mathrm{t} \\
& =(2 * 10,29)-10,848 \\
& =20,58-10,848 \\
& =9,732
\end{aligned}
$$


Perhitungan pemulusan Tren

$$
\begin{aligned}
\text { bt } & =\alpha 1-\alpha\left(S^{\prime} t-S^{\prime \prime} t\right) \\
& =0,1 / 1-0,1 *(10,29-10,848) \\
& =0,1 / 0,9 *(-0,558) \\
& =-0,62
\end{aligned}
$$

c. Proses ketiga yaitu melakukan proses peramalan (forecast) pada periode ke 4 yaitu periode April 2019 berdasarkan data periode 3 bulan sebelumnya yang sudah dilakukan proses perhitungan yaitu periode Januari, Februari, dan Maret 2019. Untuk menghitung peramalan (forecast) pada periode April 2019 dibutuhkan hasil perhitungan at (3) dan bt(3) pada perhitungan periode sebelumnya yaitu periode April 2019. Berikut merupakan hasil perhitungan forecast pada periode April 2019:

$$
\begin{aligned}
\mathrm{Ft}+\mathrm{m} & =a t+b t m \\
& =9,732+(-0,62)(1) \\
& =9,11
\end{aligned}
$$

Data tersebut kemudian disajikan didalam tabel peramalan penjualan untuk periode 1 tahun kedepan. Hasil perhitungannya yaitu seperti pada tabel di bawah ini.

Tabel 7. Penjualan 1 Tahun ke De
\begin{tabular}{|l|l|c|}
\hline No & Bulan & Penjualan \\
\hline 1. & Januari & 5 \\
\hline 2. & Februari & 6 \\
\hline 3. & Maret & 3 \\
\hline 4. & April & 5 \\
\hline 5. & Mei & 6 \\
\hline 6. & Juni & 4 \\
\hline 7. & Juli & 5 \\
\hline 8. & Agustus & 6 \\
\hline 9. & September & 5 \\
\hline 10. & Oktober & 6 \\
\hline 11. & November & 6 \\
\hline 12. & Desember & 6 \\
\hline
\end{tabular}

Hasil diatas merupakan peramalan yang dapat digunakan sebagai salah satu media untuk membantu perusahaan dalam menentukan target penjualan di periode yang akan datang. Perhitungan tersebut dilakukan dengan menggunakan proses rata - rata dari data tiga bulan sebelumnya. Sehingga peramalan yang dilakukan tidak harus selalu satu tahun kedepan. Namun bisa saja hanya meramalkan per bulan saja atau per triwulan berdasarkan kebutuhan dari perusahan itu sendiri.

\section{KESIMPULAN}

Perangkingan produk menggunakan metode SAW dapat menghasilkan urutan penjualan terbaik yang telah dilakukan oleh perusahaan citragrand. Perangkingan dilakukan dengan menggunakan kriteria - kriteria yang telah disepakati dan dinilai berdasarkan kriteria tersebut. Sehingga tiap - tiap produk mendapatkan nilai masing - masing. Dari kriteria yang ada, terbagi menjadi dua jenis yaitu cost dan benefit, dimana cost yaitu jika semakin rendah nilainya maka semakin baik. Sedangkan benefit yaitu semakin tinggi nilainya semakin baik.

Setelah melakukan perangkingan, juga dilakukan peramalan penjualan (forecasting) untuk satu tahun kedepan. peramalan dilakukan dengan menggunakan metode Double Exponential Smoothing, yaitu metode pemulusan ganda dimana perhitungan peramalan dilakukan dengan melihat data dari tiga bulan sebelumnya. 
Dengan adanya sistem ini, diharapkan dapat membantu proses transaksi dan penjualan perusahaan, juga membantu perusahaan dalam menentukan target penjualan di tahun yang akan datang. Sehingga perusahaan bisa memperoleh gambaran jumlah produk yang akan terjual di tahun yang akan datang.

\section{DAFTAR PUSTAKA}

[1] Andianto, Tomy Reza, dkk., 2017. Sistem Pendukung Keputusan Pemilihan Rumah Tinggal Di Perumahan Menggunakan Metode Simple Additive Weighting (SAW) (Studi Kasus : Kota Samarinda), Prosiding Seminar Ilmu Komputer dan Teknologi Informasi. Vol. 2 (1). Samarinda. Maret 2017. 197 - 201.

[2] Sugiarto, Hari ,2016. Penerapan Metode Simple Additive Weighting Untuk Pemilihan Rumah, Indonesian Jurnal on Computer and Information Technology. Vol. 1 (1). Mei 2016. pp. $96-103$.

[3] Ariyanto, Rudy, dkk ,2017. Penerapan Metode Double Exponential Smoothing Pada Peramalan Produksi Tanaman Pangan, Jurnal Informatika Polinema. ISSN: 2407-070X. Vol. 4 (1). pp. $57-62$.

[4] Pujiati. Estri, "Peramalan Dengan Menggunakan Metode Double Exponential Smoothing Dari Brown (Studi Kasus: Indeks Harga Konsumen (IHK) Kota Samarinda)", Jurnal EKSPONENSIAL Volume 7, Nomor 1, Mei 2016, ISSN 2085-7829.

[5] Hartini, Dwi Citra, dkk ,2013. Sistem Pendukung Keputusan Pemilihan Hotel Di Kota Palembang Dengan Metode Simple Additive Weighting (SAW), Jurnal Sistem Informasi (JSI). ISSN 2085-1588 dan ISSN 2355-4614. Vol. 5 (1). pp. 546 - 565.

[6] Hadikurniawati W. dan Wardoyo R., 2015. A Hybrid Multi-Attribute Decision Making For Electrician Selection Based on AHP, SAW, and TOPSIS, Journal of Theoretical and Applied Information Technology. ISSN: 1992-8645 and E-ISSN: 1817-3195. Vol. 77 (1).

[7] S. Mallu, "Sistem Pendukung Keputusan Penentuan Karyawan Kontrak Menjadi Karyawan Tetap Menggunakan Metode SAW", Jurnal Ilmiah Teknologi Informasi Terapan, STMIK Profesional, ISSN : 2407 - 3911, 2016.

[8] Aritonang, Lerbin R. 2002. Peramalan Bisnis. Ghalia Indonesia : Jakarta

[9] Makridakis, S., Steven C Wheelwright., Victor E Mc.Gee. 2003. Metode dan Aplikasi Peramalan. Jilid 1. Edisi Revisi. Binarupa Aksara : Jakarta.

[10] A. N. Fitriana, Harliana dan Handaru, "Sistem Pendukung Keputusan Untuk Menentukan Prestasi Akademik Siswa dengan Metode SAW", Citec Journal, Vol. 2, No. 2, Februari 2015 - April 2015, ISSN: 2354-5771, 2015

[11]D. P. Y. Ardiana, L. H. Loekito, "Sistem Informasi Peramalan Persediaan Barang Menggunakan Metode Double Exponential Smoothing”, Jurnal Teknologi Informasi dan Komputer, Volume 04, Nomor 01, 2018.

[12] Mukhyi,M.A..2008Forecasting. URL:http://www. mukhyi.staff.gunadarma.ac.id/Downloads/file s/9309/FORECASTING.pdf. Diakses pada tanggal 15 Mei 2020.

[13] I. Gunawan, "Metode penelitian kualitatif,” Jakarta Bumi Aksara, 213.

[14] duniapemrograman, "Perhitungan Sistem Pendukung Keputusan Metode SAW". Diakses pada 9 Mei 2020, dari https://duniapemrogramanque.blogspot.com/2019/07/simpleadditive-weighting-saw.html. 